Revista lus et Praxis, Año 20, No 1, 2014, pp. 397 - 416

ISSN 0717 - 2877

Universidad de Talca - Facultad de Ciencias Jurídicas y Sociales

"Revisión del arbitraje como mecanismo de resolución de conflictos en el

Derecho societario (obligatoriedad y arbitrabilidad).

Formulación de una propuesta en aras de la modernización"

M. Fernanda Vásquez Palma

Colaboración recibida el 9 de abril y aprobada el 25 de abril de 2014

\title{
Revisión del arbitraje como mecanismo de resolución de conflictos en el Derecho societario (obligatoriedad y arbitrabilidad). Formulación de una propuesta en aras de la modernización*
}

M. Fernanda Vásquez Palma**

\section{Introducción}

El arbitraje es de frecuente utilización en Chile en diversas materias de índole privada, fundamentalmente debido a su carácter forzoso, lo que ha dotado a esta institución de una particular fisonomía. Respecto del Derecho societario esta relación se acentúa, en importancia y utilización, debido a las necesidades que las sociedades presentan en cuanto a requerir una justicia apropiada para la resolución de sus conflictos, y la forma como está concebido el arbitraje normativamente, de manera que resulta fundamental su revisión y análisis, sobre todo si consideramos el fortalecimiento que el arbitraje ha experimentado en nuestro país en estos últimos años, en cuanto institución jurídica, y el especial proceso de modernización que vive el Derecho societario tanto desde una óptica de Derecho comparado como interno.

El marco jurídico que regula el arbitraje en relación al Derecho societario presenta normas dispersas en el Código Orgánico de Tribunales (COT); Código de Comercio (Cco.) y leyes especiales, a las que deben sumarse las normas de carácter general contempladas en el Código de Procedimiento Civil (CPC). Esta primera lectura arroja un problema relevante no solo por la disgregación, sino también por las divergencias existentes entre ellas.

El Art. 227 numeral $4^{\circ}$ del COT prescribe el sometimiento a arbitraje forzoso de: "Las diferencias que ocurrieren entre los socios de una sociedad anónima, o de una sociedad colectiva o en comandita comercial, o entre los asociados de

\footnotetext{
* Este comentario se enmarca en el proyecto de investigación Fondecyt regular № 1130376, titulado "La modernización del Derecho societario en Chile: Un análisis sincrónico a partir de las políticas legislativas adoptadas en Derecho comparado".

** Profesora Asociada Derecho privado, Facultad de Ciencias Jurídicas y Sociales, Universidad de Talca. Doctora en Derecho, Universidad Complutense de Madrid. Correo electrónico: mfvasquez@utalca.cl.
} 
una participación, en el caso del artículo 415 del Código de Comercio"n; por su parte, el Art. $352 \mathrm{~N}^{\circ} 10$ del CCo. establece que en las sociedades colectivas mercantiles la escritura social debe expresar: "Si las diferencias que les ocurran durante la sociedad deberán ser o no sometidas a las resolución de arbitradores, y en el primer caso, la forma en que deba hacerse el nombramiento"; seguidamente, el Art. 415 del CCo., dispone, a propósito de la disolución y liquidación de una sociedad comercial colectiva, que: "Si en la escritura social se hubiera omitido hacer la designación que indica el número 10 del artículo 352, se entenderá que las cuestiones que se susciten entre los socios, ya sea durante la sociedad o al tiempo de la disolución, serán sometidas a compromiso"; finalmente el Art. 441 de este último cuerpo normativo establece: "Las diferencias que ocurran entre los accionistas, los accionistas y la sociedad o sus administradores o liquidadores, y la sociedad y sus administradores o liquidadores, deberán ser resueltas por medio de arbitraje. El estatuto deberá indicar: 1. El tipo de arbitraje y el número de integrantes del tribunal arbitral (...); 2. El nombre o la modalidad de designación de los árbitros y sus reemplazantes. En silencio del estatuto, los árbitros serán designados por el tribunal de justicia del domicilio social"2.

A estas disposiciones se suman los Arts. $4^{\circ}$ y 125 de la Ley de Sociedades Anónimas (LSA). El primero señala que la escritura social deberá expresar: "N¹0. La naturaleza del arbitraje a que deberán ser sometidas las diferencias que ocurran entre los accionistas en su calidad de tales, o entre éstos y la sociedad o sus administradores, sea durante la vigencia de la sociedad o durante su liquidación. Si nada se dijere, se entenderá que las diferencias serán sometidas a la resolución de un árbitro arbitrador". El segundo, dispone que: "En los estatutos sociales se establecerá la forma como se designarán el o los árbitros que conocerán las materias a que se refiere el $N^{\circ} 10$ del Art. $4^{\circ}$ de la presente ley. En caso alguno podrá nominarse en ellos a una o más personas determinadas como árbitros. El arbitraje que establece esta ley es sin perjuicio de que, al producirse un conflicto, el demandante pueda sustraer su conocimiento de la competencia de los árbitros y someterlos a la decisión de la justicia ordinaria. Este derecho no podrá ser ejercido por los directores, gerentes, administradores y ejecutivos principales de la sociedad. Tampoco por aquellos accionistas que individualmente posean, directa o indirectamente, acciones cuyo valor libro

\footnotetext{
1 Este régimen también es aplicable a las sociedades de responsabilidad limitada de conformidad al Art. $4^{\circ}$ de la Ley No 3.918, sobre Sociedad de Responsabilidad Limitada, de 14 de marzo de 1923.

2 Este artículo se agregó por la letra c) del número 1 del artículo 17 de la ley 20.190, ley que Introduce adecuaciones tributarias e institucionales para el fomento de la industria de capital de riesgo y continúa el proceso de modernización del mercado de capitales, 5 de junio de 2007.
} 
o bursátil supere las 5.000 unidades de fomento, de acuerdo al valor de dicha unidad a la fecha de la presentación de la demanda"3.

De la lectura de estos preceptos se puede afirmar que el arbitraje en materia de sociedades plantea en Chile básicamente cuatro inquietudes fundamentales: el cuestionamiento de su obligatoriedad; su arbitrabilidad; la formalidad del acuerdo; y el ámbito de aplicación subjetiva. En el presente texto nos referiremos a los dos primeros puntos, a partir de la revisión de la doctrina jurisprudencial dictada en los años recientes ${ }^{4}$, con el objeto de visualizar los posibles cambios que requiere esta materia en pos de su modernización.

\section{Sobre la obligatoriedad del arbitraje}

El arbitraje forzoso es aquél impuesto imperativamente por la ley como único procedimiento para resolver determinados litigios. A partir de un mandato legal se excluye la competencia de los tribunales ordinarios otorgándoselo a los árbitros para conocer de determinados asuntos.

Pues bien, de las disposiciones antes citadas es posible advertir-desde una perspectiva general- lo siguiente:

a. En primer lugar, el legislador emplea el vocablo "diferencias" sin acotar bien su contenido. Sobre la base de ello, habría que concluir que se trata de una noción amplia que abarca todo tipo de conflictos o diferencias que puedan surgir entre los socios de una sociedad comercial. Por otra parte, la normativa es equívoca al emplear vocablos que llevan a confusión ("...serán sometidas a compromiso", "...serán sometidas a la resolución de arbitradores"). Lo anterior carece en realidad de una mayor justificación, de manera que las distinciones efectuadas sólo evidencian una comprensión deficitaria de la institución.

b. De la conjugación de estas normas no queda claro si el arbitraje es forzoso siempre o solo lo es si las partes nada han señalado a este respecto ${ }^{5}$. Si las partes lo han previsto expresamente en sus estatutos, no hay nada que discernir,

\footnotetext{
3 Este inciso se agregó por el Art. 54 del artículo $2^{\circ}$ de la ley 20.382, que introduce perfeccionamientos a la normativa que regula los gobiernos corporativos de las empresas, de 20 de octubre de 2009, con vigencia a partir del $1^{\circ}$ de enero de 2010.

4 Los dos últimos ya los hemos analizado, por lo que nos remitimos a lo señalado en su oportunidad. Véase: VÁsquez Palma, María Fernanda (2009): Arbitraje en Chile. Análisis crítico de su normativa y jurisprudencia (Santiago, Ed. LegalPublishing), pp. 484-500.

5 Este es, por lo demás, el criterio doctrinal mayoritariamente afirmado, a modo de ejemplo, Véase: Varela Morgan, R., "Dificultades entre socios, ¿Tribunales ordinarios o justicia arbitral". Disponible en: www.microjuris.cl, quien comentando la sentencia antes expuesta (Capdeville con Plaza) esgrime antecedentes históricos para señalar que el Art. 415, a propósito de la palabra "designación", no trata de resolver el problema de la falta de nombramiento de los arbitradores sino el que surge cuando la escritura no dispone si las dificultades en cuestión serán resueltas por la justicia ordinaria o por arbitradores; Aylwin Azocar, Patricio (2005): El juicio arbitral, 5ª edición (Santiago de Chile, Ed. Jurídica),
} 
pues la fuerza obligatoria del contrato lo aclara. La jurisprudencia en este punto ha sido un tanto vacilante, por una parte encontramos una línea que plantea la obligatoriedad del arbitraje frente a la existencia de una cláusula arbitral; mientras que otra es aún más enfática al señalar que el arbitraje societario establecido en el Art. $227 \mathrm{~N}^{\circ} 4$ del COT es obligatorio y si las partes estipulan otra cosa aquello adolecería de nulidad absoluta, por contravenir una norma de orden público ${ }^{6}$. Esta última tendencia es la que se ha consolidado con el paso de los años, lo que presenta problemas relevantes para la institución arbitral y los principios que debieran regirla.

c. En efecto, como ya he expresado ${ }^{7}$, lo cierto es que el arbitraje obligatorio debiera ser derogado de lege ferend $a^{8}$, pues se afecta tanto a la institución arbitral como a las partes. Desde la primera perspectiva, debe comprenderse que este instituto se cimienta en la autonomía de la voluntad de las partes, de manera que resulta un contrasentido obligarlas a someterse al mismo; desde el segundo escenario, debe considerarse que la decisión de éstas queda suprimida sin fundamentos, aun cuando se trata de derechos disponibles, y con ello se impide que puedan hacer uso de la tutela efectiva (Art. $19 \mathrm{~N}^{\circ} 26 \mathrm{CPE}$ ), y se afecte la igualdad de las personas (Art. $19 \mathrm{~N}^{\circ} 1$ inc. $1^{\circ} \mathrm{CPE}$ ), lo que nos obliga a cuestionar decididamente esta normativa sobre la base de principios constitucionales que se encuentran actualmente vulnerados ${ }^{9}$.

Frente a ello, cabe recordar que el reconocmiento del arbitraje como una institución y no un simple instrumento ${ }^{10}$, es una valoración que se encuentra

p. 97. En contra, Colombo Campbell, J. (2004): La Competencia, $2^{a}$ edición (Santiago, Editorial Jurídica de Chile), pp. 476 y ss., quien no hace distinción sobre la materia al hablar de los arbitrajes forzosos.

6 Véase: Sentencia pronunciada por la Corte Suprema, 31 de agosto de 2006, en el asunto "Capdeville Muñoz, Rosa c/ Plaza González, Eulalia y otro". Con un matiz diferenciador, encontramos una sentencia anterior de la Corte Suprema, 19 de julio de 2001, en causa "Patricio Favio Martínez Fernández con Jaime Antonio Arriagada Gallardo".

7 Véase: Vásquez Palma, María Fernanda (2009): Arbitraje en Chile. Análisis crítico de su normativa y jurisprudencia (Santiago, Ed. LegalPublishing), pp. 131-145.

8 El Anteproyecto de Ley General de Arbitraje realizado durante el año 2013 en el Ministerio de Justicia, así lo contempla. La Comisión redactora de este Anteproyecto estuvo conformada por los Profesores: A. Romero; A. Jana; C. Maturana; M.F. Vásquez; J. Irarrázabal; y E. Mereminskaya.

9 En el mismo sentido, véase: Jequier Lehuedé, E. (2011): “El arbitraje forzoso en Chile (Un examen de constitucionalidad en el ordenamiento jurídico chileno)", en: Estudios Constitucionales (Año 19, № 2), pp. 446-470.

${ }^{10}$ Distinción que prontamente realizó L. Diez Picazo al señalar que el arbitraje no es un contrato, sino una institución de solución privada de un conflicto de intereses, DıŁz Pıcazo, José Luis (1954): "El pacto compromisorio y la nueva ley de arbitraje", en $A D C$, p. 1160. Actualmente existe pleno consenso sobre este hecho en la doctrina, Véase: entre otros, CORDÓn MORENO, F. (1995): El arbitraje en el Derecho español: interno e internacional (Pamplona, Aranzadi), p. 57; GASPAR LeRA, S. (1998): El ámbito de aplicación del arbitraje (Pamplona, Aranzadi), pp. 52-53. 
suficientemente asentada hoy en día tanto en la doctrina especializada como en las diversas legislaciones que tratan esta materia. Una vez incorporada esta modalidad al ordenamiento jurídico, el arbitraje se convierte en un verdadero derecho de las personas en orden a solucionar las controversias que se encuentran dentro del ámbito de su libre disposición, derecho que goza de un carácter marcadamente potestativo, de modo que impide que alguien pueda ser obligado al mismo sin su previa aprobación o consentimiento ${ }^{11}$. Empero, aun cuando tal derecho no tuviere un reconocimiento expreso, encontraría igualmente su justificación y consiguiente existencia en el reconocimiento a la libertad de los ciudadanos y a la autonomía de la voluntad de las personas para brindarse una especial forma de justicia.

d. El arbitraje regulado en la LSA merece reflexiones adicionales, debido a la imprecisión y contradicción de las normas que lo regulan (Art. $4^{\circ} \mathrm{N}^{\circ} 10$ y 125). La primera disposición prescribe que se deberá señalar en la escritura social la naturaleza del arbitraje a que se someterán las partes por conflictos derivados de la sociedad y si ésta nada señala, la ley entiende que deberá conocer de ellas un árbitro arbitrador. Se aprecia de ello que el legislador no deja claro si el arbitraje constituye un pacto obligado para este tipo de sociedades, o bien, si elegida esta vía, deberá especificarse su naturaleza. Si bien podríamos inclinarnos por la primera alternativa sobre la base de lo prescrito por el Art. 227 del COT, rápidamente cambiamos de parecer al leer la segunda de estas disposiciones. En efecto, ésta nos indica que el "demandante" podría apartarse "del arbitraje que establece esta ley" y someter la diferencia a la justicia ordinaria una vez que surja el conflicto, de manera que lo primero que destaca esta norma es precisamente la falta de obligatoriedad o, a lo menos, un forzamiento nebuloso o disminuido.

e. No es fácil comprender esta última disposición, primero, pues no clarifica por qué se otorga tal facultad sólo a un actor jurídico (demandante), y segundo, por la ambigüedad del lenguaje utilizado. Esto ha provocado discusiones sobre la intelección de este precepto que aún no ha sido dilucidado del todo ${ }^{12}$. En nuestra opinión, la expresión "Arbitraje que establece la ley", debe entenderse

\footnotetext{
${ }^{11}$ Ruiz Jiménez, J.L. (2007): Análisis crítico del sistema nacional español de arbitraje de consumo (San Sebastián, Instituto Vasco de Derecho Procesal), pp. 44-45.

${ }^{12}$ A modo de ejemplo, véase: Jequier Lehuedé, E. (2011): "El arbitraje forzoso en Chile (Un examen de constitucionalidad en el ordenamiento jurídico chileno)", en: Estudios Constitucionales (Año 19, № 2), pp. 446-470; Vásquez Palma, María Fernanda (2009): Arbitraje en Chile. Análisis crítico de su normativa y jurisprudencia (Santiago, Ed. LegalPublishing), pp. 473-480; TORRES, O. "El arbitraje en la Ley de Sociedades Anónimas". Disponible en: página web de la Cámara de Comercio de Santiago (CAM), http://www.camsantiago.cl/articulos_online_3.htm [visitado el 15/12/2013]; Morand ValDIVIESo, L. (2007): "Jurisdicción arbitral y justicia ordinaria en sociedades anónimas", en: Libro homenaje al Profesor Patricio Aylwin Azócar (Santiago, Ed. Jurídica de Chile), pp. 331-340; Rossel CowPer, S.
} 
en su sentido natural y obvio, esto es, aquél fijado que se dispone fijar en los estatutos sociales (Art. $4^{\circ} \mathrm{N}^{\circ} 10$ y 125 ); por su parte, en cuanto a la delimitación del término "sustracción", considero que tal facultad no puede ejercerse frente a una cláusula arbitral válidamente pactada, pensar lo contrario implicaría desconocer la fuerza obligatoria del contrato (Art. 1545) ${ }^{13}$, lo que carecería de todo fundamento y justificación ${ }^{14}$. A partir de ello se desprende que la potestad conferida al demandante sólo se plantearía cuando nada se hubiere señalado sobre la materia ${ }^{15}$. Tal tesis se expuso con claridad por la CS, con fecha 24 de agosto de 1992, en causa "Kotliarenco con Banco de Chile", en que acogiendo un recurso de queja, expresó:

"El arbitraje que establece la Ley de sociedades anónimas es aquel supletorio para el caso que las partes nada dispongan en la escritura social, respecto del cual es posible substraerse para entregar el conocimiento del conflicto a los tribunales ordinarios de justicia. Si el arbitraje se pacta y reglamenta expresamente en la escritura social, no procede la opción a que alude el inciso $2^{\circ}$ del artículo 125 de la ley No 18.046".

La consecuencia obvia de lo anterior es que el arbitraje se entiende obligatorio sólo si se pacta. Si las partes nada señalan sobre esta materia en los estatutos, el demandante podría sustraer la materia para llevarlo a la judicatura ordinaria, de manera que es éste el que arrastra al resto de las partes con su elección, pero no lo impone la ley de manera forzosa. Aquél podría iniciar tanto la vía ordinaria, como la arbitral a partir de su mera voluntad, he aquí la singularidad de este arbitraje. En otras palabras en las sociedades anónimas el arbitraje siempre se debiera entender como voluntario, a lo menos para el demandante, de manera que la única forma que aquél tiene para primar por

(1992): "Comentario a sentencia de Corte Suprema de 24 de agosto de 1992", en: Revista de Derecho y Jurisprudencia y Gaceta de los Tribunales (T., LXXXIX), p. 131.

${ }^{13}$ En la búsqueda de su exacto entendimiento, cabe mencionar una sentencia pronunciada por un tribunal arbitral en el juicio caratulado "Cristián Mosso y Compañía Limitada; con Cooperativa Rural Eléctrica Llanquihue Limitada", que mantuvo una posición tibia sobre el particular al expresar: "El arbitraje que establece esta ley es sin perjuicio de que, al producirse un conflicto, el demandante pueda sustraer su conocimiento de la competencia de los árbitros y someterlo a la decisión de la justicia ordinaria. Esta norma deja a las partes la forma como se designarán los árbitros, de común acuerdo entre los socios, o por designación judicial por ejemplo, permitiendo luego sólo al demandante, si así lo estima, conferir competencia a los tribunales comunes". Dicha sentencia fue confirmada por la Corte Suprema con fecha 26 de abril de 2006, sin objetar ni contradecir tal razonamiento.

${ }^{14}$ Aun si se cuestionara el carácter contractual de los estatutos sociales, habría que recordar lo dispuesto en el Art. 22 y 30 de la Ley de Sociedades Anónimas.

${ }^{15}$ En este mismo sentido, Morand Valdivieso, L. (2007): "Jurisdicción arbitral y justicia ordinaria en sociedades anónimas", en: Libro homenaje al Profesor Patricio Aylwin Azócar (Santiago, Ed. Jurídica de Chile), pp. 330-331. 
sobre la elección de la justicia ordinaria será por medio de la fuerza de un pacto arbitral previo (Art. 1545), lo que se justifica por la fuerza vinculante del mismo y no por la voluntad del legislador, a diferencia de lo que sucede en el resto de los arbitrajes societarios ya analizados (Art. 415 Cco.) que pregonan justamente la idea contraria, esto es, que el arbitraje es obligatorio por medio de su reglamentación expresa o frente a una ausencia de elección por las partes sobre la forma como se resolverían los conflictos suscitados.

En el mismo sentido, se pronuncia la CA de Valdivia con fecha 30 de agosto de 2000, en causa "Óscar Carrasco A., Enrique Tapia W.; Jorge Rodríguez A.; José Fernández R.; Franklin Geldres A.", que al confirmar una sentencia de primera instancia, señaló a este respecto:

"Corresponde acoger la excepción dilatoria de incompetencia del tribunal, si esta se basa en que la demanda debe presentarse ante un tribunal arbitral, dado que se trata de un conflicto entre socios de una sociedad anónima, en cuyos estatutos se establece una cláusula compromisoria para someter justamente a arbitraje dichos conflictos, no siendo pertinente en el caso aplicar lo señalado en el inciso segundo del artículo 125 de la ley 18.046, el cual sólo operaría en silencio de los propios estatutos sociales, ya que sería por lo demás contradictorio que si los estatutos previeron la forma de designación del árbitro y su calificación, pueda a este respecto el demandante, persona siempre regida por los estatutos sociales, desconocer la cláusula arbitral pactada"16.

La citada sentencia fue confirmada por la CS, con fecha 9 de noviembre de 2000. Este mismo planteamiento fue esgrimido por la CS con fecha 10 de abril del mismo año, en causa "Luis Germán Villalobos con Sociedad Golden Sat S.A.", frente a un recurso de protección interpuesto, oportunidad en que confirmó la sentencia pronunciada por la CA de San Miguel y sentenció:

\footnotetext{
${ }^{16}$ En este caso, frente a una demanda presentada ante el tribunal ordinario, el demandado opuso la excepción dilatoria de incompetencia del tribunal contemplada en el Art. $301 \mathrm{~N}^{\circ} 1$ del CPC, en razón de que en el pacto social se había acordado una cláusula compromisoria. La parte demandante, evacuando el traslado conferido, solicitó el total rechazo de la excepción opuesta, por cuanto en su consideración la actual normativa referente a las sociedades anónimas, había modificado el régimen jurídico respecto del órgano encargado de dirimir los conflictos citados al interior de una sociedad, en tal sentido arguye, el artículo 125 de la ley № 18.046 (Sobre Sociedades Anónimas, 22 octubre 1981) contradice la obligatoriedad del arbitraje al dejar a la voluntad del demandante el acudir al arbitraje o a la justicia ordinaria, por lo cual al ejercerse la acción correspondiente ante la justicia ordinaria se entiende renunciada la facultad de acudir a la justicia arbitral. El tribunal acogió la excepción de incompetencia argumentando que: "La facultad a que alude el inc. $2^{\circ}$ del artículo 125 del citado cuerpo legal, operaría sólo en silencio de los propios estatutos sociales. Agrega que sería, por lo demás, contradictorio que si los estatutos previeron la forma de designación del árbitro y su calificación, pueda a este respecto el demandante, persona siempre regida por los estatutos sociales, desconocer la cláusula arbitral pactada".
} 
"En la escritura de Constitución de Sociedad Golden Sat Sociedad Anónima, en su título octavo, señala expresamente 'Todas las diferencia(sic), dudas o dificultades que ocurran ente los accionistas o entre estos, y la sociedad y/o sus administradores o entre estos últimos entre sí con motivo de la validez, aplicación, interpretación o por cualquier otra causa, sea durante la vigencia o estando pendiente su liquidación, serán resueltas por un árbitro arbitrador designado por las partes, a falta de acuerdo, por la justicia ordinaria.

Los hechos reconocidos por las partes, en sus presentaciones que rolan en autos, evidencian que entre ellos han surgido divergencias o diferencias respecto de la aplicación e interpretación de los preceptos y normativas del referido contrato de sociedad, situación que debe ser resuelta de la manera que allí se previó, esto es, la constitución del Tribunal Arbitral (Considerandos $4^{\circ}, 5^{\circ}$ y $6^{\circ}$ de la sentencia de la Corte de Apelaciones). Corresponde acoger la excepción dilatoria de incompetencia del tribunal, si esta se basa en que la demanda debe presentarse ante un tribunal arbitral, dado que se trata de un conflicto entre socios de una sociedad anónima, en cuyos estatutos se establece una cláusula compromisoria para someter justamente a arbitraje dichos conflictos, no siendo pertinente en el caso aplicar lo señalado en el inciso segundo del artículo 125 de la ley 18.046, el cual sólo operaría en silencio de los propios estatutos sociales, ya que sería por lo demás contradictorio que si los estatutos previeron la forma de designación del árbitro y su calificación, pueda a este respecto el demandante, persona siempre regida por los estatutos sociales, desconocer la cláusula arbitral pactada".

De manera más reciente, podemos citar la sentencia pronunciada por la Excma. Corte Suprema con fecha 22 de julio de 2008, recaída en recurso de casación en el fondo interpuesto en contra de la sentencia del $2^{\circ}$ Juzgado de Letras de Osorno, dictado en juicio ordinario de disolución de sociedad e indemnización de perjuicios caratulado "Agrícola y Ganadera Arco Iris SA con Agrícola Ganadera y Forestal Los Ríos $\mathrm{SA}^{\prime \prime}$, rol N¹2.353, que acogió la excepción de incompetencia absoluta del tribunal disponiendo que las partes debían recurrir ante un juez árbitro. La CS acogió el recurso de casación en el fondo otorgando competencia al tribunal ordinario. Para ello consideró que no correspondía aplicar el Art. $227 \mathrm{~N}^{\circ} 4$ del COT, puesto que las controversias que surjan de las sociedades anónimas se encuentran reguladas por la LSA, y en dichas disposiciones (Art. $4^{\circ} \mathrm{N}^{\circ} 10$ y 125), no cabe hablar de arbitraje forzoso. Agrega que de la lectura de la cláusula $29^{\circ}$ de los estatutos se advierte que, si bien las partes disponen que un juez árbitro arbitrador será quien resolverá los conflictos que se pudieren suscitar (dentro de las cuales se encuentra la que originó el juicio), en la parte final acuerdan voluntariamente la supervivencia de la potestad del Art. 125. Sobre la base de ello, argumenta que "corresponde hacer la distinción entre la naturaleza del arbitraje y la posibilidad de optar, 
siendo esta última la que se dejó expresamente consignada en el corolario de la cláusula vigésimo novena de la convención en estudio"17.

Queda en total evidencia, entonces, que la interpretación que ha de darse al aludido Art. 125 es el que acabamos de señalar. Sostener lo contrario implicaría aceptar que la facultad conferida al demandante es amplia y puede pasar incluso por sobre lo acordado en los estatutos sociales, lo que resulta un despropósito y carece de toda justificación ${ }^{18}$.

Sobre por qué tal facultad sólo se entrega al demandante, no existe una respuesta satisfactoria que justifique la citada disposición, de manera que no podemos sino entender que se trata de un precepto arbitrario que intenta favorecer al litigante inicial. A partir de lo anterior, se genera una nueva pregunta: ¿Qué ocurre si simultáneamente las partes presentan sus respectivas demandas ante tribunales diversos? El asunto es complejo por cuanto el legislador confiere esta facultad a un "actor procesal" suponiendo que será uno solo, sin embargo, olvida que tal posición jurídica se puede obtener mediante procedimientos diversos, así por ejemplo, podría suceder que uno de los afectados comience un juicio arbitral para resolver un determinado conflicto, y simultáneamente otro de los afectados "demande" sobre el mismo conflicto ahora en sede ordinaria, ¿cuál debería prosperar si consideramos que ambos sujetos fueron "demandantes" en sus respectivas causas? Dado que el legislador no resuelve tal inconveniente, habría que dirimir la disputa atendiendo a la temporalidad, es decir, quién demandó primero, intentando en ello aplicar la literalidad de la norma.

Bajo la lógica expuesta, cabe adicionar que si al demandante se le confiere la facultad de demandar en sede ordinaria cuando las partes no han convenido un arbitraje, es decir, cuando nada han señalado sobre la forma de resolver sus conflictos, con mayor razón habría que sostener que las partes podrían convenir anticipadamente esta elección, en el sentido de establecer que frente a los conflictos que emerjan acudirán a la justicia ordinaria para la resolución de conflictos. Todo lo expresado nos lleva a establecer que a pesar de tratarse éste de un sistema sui géneris, no puede predicarse respecto de esta materia la existencia de un arbitraje completamente obligatorio.

En relación a la última parte de esta disposición, debemos considerar que la reforma efectuada por la Ley $N^{\circ} 20.382$ limita este derecho respecto de ciertas personas (Directores, gerentes, administradores, ejecutivos principales

\footnotetext{
17 En un sentido similar, puede consultarse la sentencia pronunciada por la I. Corte de Apelaciones de Santiago de fecha 27 de septiembre de 2007, rol № 2250-2006.

${ }^{18}$ Con todo, existen sentencias que han considerado que el arbitraje en materia de sociedades anónimas es forzoso de conformidad al Art. 227 del COT. Las veremos más adelante.
} 
o accionistas allí singularizados) $)^{19}$. Se intenta con ello impedir que insiders y accionistas importantes puedan sustraer del arbitraje las cuestiones que se puedan ventilar en el curso de la vida social ${ }^{20}$. Considero que no se trata de una reforma relevante, si bien se pretendió brindar protección a los accionistas minoritarios, no se ve con claridad cómo ello podría lograrse, pues el hecho de sustraer el conflicto de la competencia arbitral para llevarlo a la justicia ordinaria, en ningún caso podría ser entendido como una posible vulneración de aquéllos. Esto solo demuestra una débil comprensión de la institución arbitral y la pérdida de una valiosa oportunidad para revisar esta materia y modificar el contenido de estos preceptos $\left(4^{\circ} \mathrm{N}^{\circ} 10\right.$ y 125$)$ en dos direcciones: primero clarificando el hecho que el arbitraje es voluntario, y segundo, delimitando ciertas reglas que definan la forma y arbitrabilidad de las materias societarias que pueden someterse a un arbitraje ${ }^{21}$.

\section{Sobre la arbitrabilidad}

a. Nadie puede discutir que las materias societarias pertenecen al orden privado del Derecho y son de tipo patrimonial, de manera que su arbitrabilidad debiera estar exenta de dudas; no obstante ello, esta afirmación presenta variados matices, de manera que debe analizarse con cuidado. Los temas que se han puesto normalmente en tela de juicio dicen relación con los conflictos surgidos entre la sociedad y administradores, la impugnación de los acuerdos de los órganos colectivos (tanto por los socios como por terceros), la exclusión del socio y la liquidación de cuota, entre otros ${ }^{22}$.

Para dilucidar esta cuestión debemos considerar que en el arbitraje societario la arbitrabilidad se circunscribe al reconocimiento del principio de autonomía de los socios fundadores para incluir en los estatutos las cláusulas que consideren oportunas, respetando las leyes y principios configuradores de la sociedad de que se trate; y en segundo lugar, sometiendo a arbitraje las materias que sean de libre disposición conforme a derecho. La regla general es que las materias societarias gozan de tal carácter, y no lo harán cuando se afecten intereses particulares de terceros siguiendo, por tanto, el criterio que ya antes esbozamos

\footnotetext{
${ }^{19}$ Sobre esta materia, véase: VÁsquez Palma, María Fernanda (2013): Sociedades (Santiago, Ed. Thomson Reuters), pp. 737-745.

${ }^{20}$ Informe Comisión de Hacienda, Historia de la ley № 20.382, Boletín № 5.301-05, p. 63.

${ }^{21}$ A modo de ejemplo, véase reforma realizada por la Ley de arbitraje $N^{0} 11 / 2011$, en España, que introduce los artículos 11 bis y 11 ter.

22 Sobre esta materia, véase: Jequier Lehuedé, E. (2013): El arbitraje en el Derecho chileno de sociedades. Arbitrabilidad del conflicto societario mercantil (Santiago, Ed. LegalPublishing-Thomson Reuters).
} 
sobre la materia ${ }^{23}$. En este contexto, se debe recordar que la autonomía de la voluntad se presenta de diferentes formas según el tipo de sociedad, en las sociedades de personas tienen un amplio margen dado que no confluyen normalmente intereses de terceros, sino que se trata de un arbitraje creado por los socios para dirimir sus propios conflictos; en cambio, las sociedades capitalistas presentan un tinte institucional importante donde confluyen variadas normas de orden imperativo a las que deben someterse los socios indefectiblemente $y$, por tanto, las cláusulas arbitrales podrían encontrarse más limitadas ${ }^{24}$. Derivado de ello, no basta con pactar el arbitraje en una sociedad, pues normalmente se plantea la materia en términos genéricos, habrá que esperar el tipo de controversia que surja para determinar si es susceptible de ser arbitrada dependiendo de los derechos involucrados ${ }^{25}$.

b. En relación al ámbito de aplicación material de los conflictos societarios, debemos partir por aceptar que no existe una norma que, de manera general, zanje este punto ${ }^{26}$. De la conjugación de aquéllas es posible colegir que se trata de todo tipo de controversias suscitadas a raíz del contrato social, independiente de la temporalidad del mismo, es decir, aquellos que se provocan con motivo de su surgimiento, funcionamiento o término de la misma, contemplando en dichas nociones el amplio abanico de opciones que originan dichos conflictos. Consideramos que esta es la correcta interpretación y el hecho que el Art. 352 № 10 sólo aluda a "(...) las diferencias que les ocurran durante la sociedad(...)", no contraría tal razonamiento, por cuanto, si bien dicha norma nada expresa

${ }^{23}$ En Derecho comparado se trata de una temática ampliamente debatida, a modo de ejemplo, Véase: Carazo Liébana, María José (2005): El arbitraje societario (Madrid, Ed. Marcial Pons), pp. 85 y ss.; MuÑoz Planas, José María (1978): "Algunos problemas del arbitraje en materia de sociedades mercantiles", en: Estudios de Derecho Mercantil en homenaje a Rodrigo Uria (Madrid, Editorial Civitas), pp. 381-490; Muñoz Planas, J.M.; Muñoz Paredes, J.M. (2000): "La impugnación de acuerdos de la junta general mediante arbitraje", en: RDM (No 238), pp. 1411-1431; Perales VISCASILlas, Pilar (2005): Arbitrabilidad y convenio arbitral (Navarra, Ed. Aranzadi); VICENT CHULIÁ, F. (2001): "El arbitraje en materia de impugnación de acuerdos sociales. Acto final", en: Anuario de Justicia Alternativa (№ 1), pp. 89-120.

${ }^{24}$ Para un detenido análisis de esta materia, véase: Vicent Chulı́, F. (2001): "El arbitraje en materia de impugnación de acuerdos sociales. Acto final", en: Anuario de Justicia Alternativa ( $\mathrm{N}^{\circ} 1$ 1), pp. 94 y ss.

${ }^{25}$ Así lo expresan, Muñoz Planas, J.M.; Muñoz Paredes, J.M. (2000): “La impugnación de acuerdos de la junta general mediante arbitraje", en: $R D M\left(\mathrm{~N}^{\circ} 238\right)$, pp. 1411-1431.

${ }^{26}$ De acuerdo al Art $227 \mathrm{~N}^{\circ} 4$ del COT se deberán someter a arbitraje "Las diferencias que ocurrieren entre los socios de una sociedad anónima, o de una sociedad colectiva o en comandita comercial, o entre los asociados de una participación, en el caso del artículo 415 del Código de Comercio". La segunda parte del Art. 415 del CCo alude a "las cuestiones que se susciten entre los socios, ya sea durante la sociedad o al tiempo de la disolución (...)"; el Art. 352 № 10 se refiere a "las diferencias que les ocurran durante la sociedad (...)"; finalmente el Art. $4^{\circ} \mathrm{N}^{\circ} 10$ de la Ley $\mathrm{N}^{\circ} 18.046$ prescribe que el arbitraje atenderá las "diferencias que ocurran sea durante la vigencia de la sociedad o durante su liquidación". 
respecto a las diferencias surgidas al tiempo de la liquidación o término de la sociedad, tampoco excluye dicho campo de acción, y si sumamos a ello que las controversias que pueden ocurrir durante una sociedad también es comprensiva de estas últimas, nada puede contrariar el hecho que, en definitiva, pueda tratarse de conflictos futuros siempre que nazcan de la sociedad. Lo anterior, guarda perfecta armonía con las bases de la institución arbitral que se entiende concebida precisamente para resolver conflictos no solo presentes, sino que también futuros.

Por otra parte se advierte que todas las normas sociales que aluden al arbitraje emplean nomenclaturas diferentes para referirse al objeto del litigio, de manera que aquél ha de entenderse en términos amplios en lo relativo a su aspecto conflictual ${ }^{27}$.

c. Otra forma en la que se presenta este problema, liga con la eficacia de la cláusula arbitral, en la medida que una materia, siendo arbitrable en principio, no pueda ser conocida en el juicio arbitral por haber quedado excluida de aquélla ${ }^{28}$. En este entendido, resulta recomendable una cláusula amplia de arbitraje sin concreción de los litigios arbitrales ${ }^{29}$, de manera que la cláusula arbitral podrá indicar ámbitos objetivos de aplicación del tipo "toda controversia o conflicto de naturaleza societaria...se resolverá definitivamente con un arbitraje..."; o bien predicar "todas las controversias derivadas de la interpretación o ejecución del contrato social serán resueltas por medio de arbitraje...". Tal formulación no debe considerarse vaga o imprecisa, sino como la más idónea por albergar todos los litigios susceptibles de surgir en el marco de las relaciones societarias que afectan derechos disponibles. En estos casos los problemas son menores, toda vez que, aunque no se refiera expresamente a determinados conflictos, se

\footnotetext{
${ }^{27}$ En efecto, el Art. 415 del CCo., alude a "cuestiones"; el Art. 352 del mismo cuerpo legal, se refiere a "las diferencias"; expresión que también es acuñada por el Art. 4 № 10 de la ley 18.046, y finalmente el Art. 125 apunta a los vocablos de "materias" y "conflictos".

${ }^{28}$ En este punto, P. Perales Viscasillas sostiene que en derecho comparado no existe unicidad de criterios, así por ejemplo en derecho italiano, la jurisprudencia no aplica en todo su rigor el principio pro arbitraje y ha sostenido que la cláusula arbitral relativa a la interpretación y ejecución de los estatutos no cubre la acción dirigida a la remoción del administrador, ni aquellas relativas a la invalidez de las decisiones adoptadas en junta general. En el derecho español, algunos autores se inclinan por la interpretación amplia derivada del principio favorable al arbitraje y porque de lo contrario el ámbito de aplicación sería muy reducido. Perales VISCASILlas, Pilar (2005): Arbitrabilidad y convenio arbitral (Navarra, Ed. Aranzadi), pp. 223-224.

${ }^{29}$ En el derecho extranjero existe una línea favorable de la extensión del arbitraje a la solución de situaciones no estrictamente litigiosas en sentido amplio. Fernández del Pozo ha señalado, en relación al caso español, que "si las partes están conformes no hay obstáculo para ello, véase Fernández del Pozo, L. (1992): "Publicidad mercantil registral del procedimiento arbitral", en: $R C D I\left(\mathrm{~N}^{\circ} 618\right)$, p. 2036; en el mismo sentido, Carazo LiéBana, María José (2005): El arbitraje societario (Madrid, Ed. Marcial Pons), p. 47.
} 
delimita perfectamente la naturaleza societaria, razón por la que las controversias surgidas a partir de aquéllas deberán ser sometidas a arbitraje.

Por el contrario, la redacción de una cláusula más estrecha plantea la inquietud de saber qué ocurrirá con aquellas materias que no se incluyeron en la citada configuración. En mi opinión, si se trata de una sociedad anónima, habría que entender que aquéllos deberán ser conocidos y resueltos por la justicia ordinaria, mientras que si se trata de otros tipos societarios, aquello carecerá de toda relevancia debido a la obligatoriedad del arbitraje, que opera con independencia de la voluntad de las partes.

A este respecto, cabe mencionar una sentencia reciente pronunciada por la Corte de Apelaciones de Santiago, con fecha 20 de mayo de 2013, en causa "Meza Bañados c/ Juez árbitro arbitrador José Gonzalo Baeza Ovalle". En esta causa, la parte demandante amplió el objeto del juicio al solicitar al árbitro que declarara la inexistencia, o en subsidio la invalidez, de un acuerdo de Directorio y se condenara a los demandados a pagar a los demandantes indemnización de perjuicios, cuyo monto y especie reservaron para el cumplimiento del fallo. El árbitro acogió la demanda en todas sus partes, y frente a este actuar los demandados dedujeron recurso de queja. La Primera Sala de la Corte de Apelaciones en cita acogió el recurso por estimar que el árbitro carecía de competencia para conocer de demandas de indemnización de perjuicios y no pudo, sin incurrir en grave falta o abuso, declarar que los demandados estaban obligados a pagar, y todavía en forma solidaria (lo que ni siquiera fue demandado), perjuicios a los actores, reservando a éstos el derecho a perseguir su naturaleza y monto en el cumplimiento del fallo, de suerte que al aceptar el juez árbitro la demanda en esta parte se ha extralimitado en sus funciones y se ha extendido a puntos que nunca pudieron ser materia de su conocimiento. Como consecuencia, se ordenó dejar sin efecto los considerandos 4 y 5 de la aludida sentencia ${ }^{30}$.

d. Más allá de ello, en la práctica, son temas recurrentes de sometimiento a arbitraje el incumplimiento del contrato de sociedad, nulidad de la sociedad, valoración de las aportaciones sociales o de acciones o participaciones, interpretación de los contratos, separación y exclusión de socios, liquidación de la participación de los socios, disolución y liquidación de las sociedades, termi-

${ }^{30}$ El fundamento de este fallo liga con la delimitación efectuada previamente en los estatutos sociales, toda vez que éstos disponían: "Toda dificultad que surja entre los socios o entre estos y la sociedad, por cualquier razón, incluso extra societaria, vale decir, relativa a negocios particulares que directa o indirectamente incidan en la gestión, operación, administración o manejo de la sociedad, como también respecto de la validez de la sociedad, sus estipulaciones, las contenidas en esta modificación, su alcance, al igual que la validez de esta cláusula, además de la interpretación de las distintas estipulaciones sociales, será resuelta por un árbitro arbitrador, en única instancia(...)". Los sentenciadores estimaron que lo demandado se encontraba fuera del radio de acción permitido por esta cláusula estatutaria. 
nación anticipada de la sociedad, indemnización de perjuicios, interpretación del aporte de los socios, realización de aportes y pago de dividendos pasivos, restricciones a la transmisibilidad de acciones y participaciones, responsabilidad y retribución de los administradores ${ }^{31}$. El arbitraje en materia de nulidad de junta general, de impugnación de acuerdos sociales, de actos del directorio o balances, constituyen temas sensibles de arbitrar en Derecho comparado ${ }^{32}$. El legislador chileno no pone freno en relación a las materias o derechos que podrán someterse a un arbitraje societario, estos límites surgen de la propia naturaleza de las materias y de la extensión de la cláusula arbitral. En estos casos, lo que ha de tener presente el árbitro es el respeto a las normas impertivas que contempla la materia.

Frente a la nulidad de las sociedades debe considerarse que el árbitro es perfectamente competente para conocer de dicho conflicto en virtud del principio de autonomía o separación del convenio arbitral ${ }^{33}$. Sobre la materia, lamentablemente no se han pronunciado los tribunales de justicia chilenos de un modo claro, un ejemplo de ello lo constituye el fallo pronunciado por la CS con fecha 26 de abril de 2006, en causa "Cristián Mosso y Compañía Limitada; con Cooperativa Rural Eléctrica Llanquihue Limitada". En este caso la parte demandada opuso la excepción de incompetencia del tribunal, señalando que si bien en los estatutos de la sociedad se convino que las dificultades, diferencias o cuestiones que se suscitaren entre los accionistas en su calidad de tales, o entre éstos y la sociedad o sus administradores, sea durante la vigencia de la sociedad o durante su liquidación, serían resueltas por un árbitro arbitrador, estas hipótesis no se daban en la especie porque lo que se discutía era precisamente la nulidad de la sociedad, de manera que antes de ocuparse de los litigios entre asociados era necesario saber si ha existido asociación. Finaliza argumentando que un litigio sobre la existencia o validez del pacto social pone en duda la jurisdicción misma del árbitro, la que se funda en el hecho de existir la sociedad con absoluto valor. Al respecto, la CS rechazó la excepción de incompetencia señalando que la nulidad del contrato de sociedad no conlleva la nulidad del pacto arbitral, pero no lo hace reconociendo el principio en comento de manera

\footnotetext{
${ }^{31}$ La arbitrabilidad de algunas de estas materias ha sido puesta en tela de juicio en el Derecho comparado. Véase: MuÑoz Planas, José María (1978): "Algunos problemas del arbitraje en materia de sociedades mercantiles", en: Estudios de Derecho Mercantil en homenaje a Rodrigo Uria (Madrid, Editorial Civitas), pp. 381 y sgtes.; VICENT Chulí, F. (2001): "El arbitraje en materia de impugnación de acuerdos sociales. Acto final", en: Anuario de Justicia Alternativa (Nº1), pp. 93-94.

${ }^{32}$ C. Molina Sandoval señala como ejemplo que en el ordenamiento argentino este tema dice relación con delitos contra la fe pública. Molina SANDOval, C. (2006): "El arbitraje en la dinámica de los conflictos societarios", en: Revista Vasca de Derecho Procesal y Arbitraje (T. XVIII), pp. 235-236.

${ }^{33}$ Sobre el tema: VÁsquez Palma, María Fernanda (2009): Arbitraje en Chile. Análisis crítico de su normativa y jurisprudencia (Santiago, Ed. LegalPublishing), pp. 211-219.
} 
categórica, sino fundamentalmente por considerar que el arbitraje societario es obligatorio o forzoso. Nótese que se trataba de una sociedad anónima, de manera que esta sentencia resulta contraria a la línea jurisprudencial antes analizada en este punto. En lo medular sentenció:

"Que el rechazo de la competencia del juez árbitro para conocer de una acción sobre nulidad del contrato de sociedad, constituye una creación doctrinaria que tiene de base un supuesto totalmente falso, como es que serían las partes quienes sustraen de la justicia ordinaria el conocimiento de este asunto. El supuesto es falso, pues las partes nada dicen sobre ello, sino que la ley así manda hacerlo. 9. Que en consecuencia, para declarar la incompetencia del juez árbitro en materia de nulidad, debiera existir una norma excepcional que reenvíe a la justicia ordinaria el conocimiento de estas materias. 10. Que esa norma no existe, sino por el contrario, la ley expresamente dispone que el arbitraje debe resolver las cuestiones que se planteen entre los socios durante la vigencia de la sociedad. 11. Antes que todo, la sociedad es un contrato cuya vigencia se prolongará hasta que una sentencia de término declare su ineficacia. 12. Que mientras el contrato de sociedad se encuentra vigente, como en la especie ocurre, es obligatorio aplicar la normativa especial que le rige, y ésta hace forzoso ventilar los conflictos societarios ante un juez árbitro. 13. Que en consecuencia, no es efectivo que la nulidad del contrato de sociedad Ileve aneja la nulidad de la "cláusula de compromiso", pues si ésta no existiere el conflicto debe ser resuelto igualmente por un árbitro arbitrador, conforme a los artículos 352 № 10 y 425 del Código de Comercio, en relación a los artículo 4 № 10 y 125 de la ley de sociedades anónimas. 14. Que en el caso sub-lite, las propias partes han dado mayor fuerza a la competencia arbitral que fija la ley, pues acordaron en la cláusula 33 de la escritura constitutiva de "Ondavisión Crell S.A.", justamente en cumplimiento del artículo $4^{\circ} \mathrm{N}^{\circ} 10$, que toda dificultad, diferencia o cuestiones que se susciten entre los socios, están sometidas a arbitraje; contrato que es una ley para ambos litigantes de este juicio".

La expulsión de un socio de la sociedad es otro de los temas que recurrentemente se someten a arbitraje en sede societaria. Al respecto, es ilustrativa una sentencia pronunciada por la CA de Concepción, que con fecha 27 de noviembre de 2002, confirmada por la CS con fecha 22 de enero de 2003, en causa "Rogers Ricardo Concha Órdenes con Sociedad de Transportes Vía Futuro SA", rechazó un recurso de protección por considerar que esta materia formaba parte de la competencia del tribunal arbitral, no obstante no indicarse de manera expresa en la referida cláusula. En lo concreto, sentenció:

"En lo relativo a la expulsión del recurrente en su calidad de socio, se debe tener presente lo dispuesto en el estatuto social. Normativa que contiene el procedimiento idóneo a que los accionistas se sometieron para resolver las dificultades o diferencias que pudieren surgir entre los accionistas en su calidad de tales, o 
entre éstos y la sociedad o sus administradores, con motivo de la interpretación, cumplimiento o terminación del presente contrato. Materia que sería resuelta sin forma de juicio y sin ulterior recurso por la persona que las partes de común acuerdo designen, en calidad de árbitro arbitrador o amigable componedor y a falta de acuerdo, la designación corresponderá a la justicia ordinaria. Con todo, las diferencias que ocurrieren entre los socios de una sociedad anónima es materia de arbitraje obligatorio, según se señala en el artículo 227 № 4 del Código Orgánico de Tribunales".

Esta sentencia resuelve a favor del arbitraje considerando -al igual que el caso precedente- que este es obligatorio, sin pronunciarse sobre la arbitrabilidad de la pretensión.

Los actos emanados del directorio también podrían ser entendidos como arbitrables. Al respeto podemos revisar un fallo pronunciado por la CA de Concepción con fecha 5 de septiembre de 2000, que rechazó un recurso de protección por considerar que esta materia formaba parte de la competencia arbitral. El recurso fue impetrado por los accionistas por estimar que habían sido objeto de una discriminación arbitraria por parte del Directorio de la sociedad. Fundaron tal recurso en el hecho que este último les había negado injustificadamente el beneficio social consistente en la solución de los Permisos de Circulación y del Seguro Automotriz Obligatorio que correspondía a todos los socios, sin distinción y respecto del cual los recurrentes fueron ilegal y arbitrariamente excluidos por acuerdo adoptado en Junta Extraordinaria de Accionistas celebrada el 13 de mayo de 2000, con lo que se les obligaba a efectuar esos gastos con cargo a sus propios medios, pues los respectivos pagos debían materializarse en un plazo que vencía el 31 de agosto de 2000. El fallo, en lo medular, señaló:

"Cabe rechazar el recurso interpuesto por los recurrentes, dado que el artículo 35 del pacto social contiene el procedimiento idóneo al que los accionistas recurrentes libremente se sometieron para resolver las dificultades o diferencias que pudieran surgir entre los accionistas en su calidad de tales, o entre éstos y la Sociedad o sus administradores, con motivo de la interpretación, cumplimiento o terminación del presente contrato, agregando que esta será resuelta sin forma de juicio y sin ulterior recurso por la persona que las partes de común acuerdo designen en calidad de árbitro arbitrador o amigable componedor y a falta de acuerdo, la designación corresponderá a la justicia ordinaria. (Considerando $3^{\circ}$ Corte de Apelaciones de Concepción)"

La administración y retiro de fondos es otra de las materias que se podrá someter a un arbitraje de acuerdo con las normas antes estudiadas. Así lo señaló la CS con fecha 19 de julio de 2001 en causa caratulada "Patricio Favio Martínez Fernández; con Jaime Antonio Arriagada Gallardo", en que rechazando un recurso de casación en el fondo expuso: 
"Que, mediante la acción deducida, el actor persigue que se ordene al demandado, su socio en la Sociedad de Responsabilidad Limitada denominada "Muñoz y Arriagada Ltda.", el reintegro a la Sociedad de los retiros practicados en exceso por el demandado, materia que de conformidad a los artículos 415 del Código de Comercio y $227 \mathrm{~N}^{\circ} 4$ del Código Orgánico de Tribunales, corresponden (sic) ser conocida forzosamente por un tribunal arbitral; en consecuencia, los sentenciadores, han hecho una correcta aplicación de las disposiciones legales atinentes al caso de que se trata; razón por la cual, el recurso en estudio adolece de manifiesta falta de fundamento".

Los conflictos entre socios se entienden incorporados al convenio arbitral, pero solo los que digan relación con la sociedad, debiendo considerar que la naturaleza del conflicto no siempre es sencilla de despejar ${ }^{34}$. Se presenta el problema de determinar si una cesión de acciones puede ser objeto de arbitraje, en tal contexto se debe considerar que la transmisión de estas acciones es un negocio jurídico externo y como tal no es factible aplicar el arbitraje pactado para la sociedad a una transferencia particular. Con todo, si lo que se discute es una eventual irregularidad del procedimiento de atribución de legitimación societaria embebido en el mecanismo limitativo, la cuestión será societaria y por tanto arbitrable porque tendrá una repercusión directa en la sociedad, pero si lo controvertido es la validez del título de transmisión, la cuestión no es arbitrable a menos que el adquirente y transmitente estén ligados por un convenio arbitral específico que no puede ser el contenido en la propia cláusula estatutaria, sino uno particular acordado para el caso.

Otro conflicto frecuente suscitado en sociedades de capitales es el de valorar la preferencia que éstas puedan tener para el pago de dividendos. Así, por ejemplo, un fallo de la CS pronunciado con fecha 24 de agosto de 1992, caratulado "Kotliarenco con Banco de Chile" resolvió que era competente la justicia arbitral y no la ordinaria - como pretendían los demandantes-, por quedar tal controversia comprendida en la cláusula arbitral correspondiente según se desprende de la interpretación de esta última. En lo concreto, expresó:

"De los autos aparece que los demandantes dedujeron, en procedimiento ordinario, una demanda en contra del Banco, para que declare que la preferencia en el pago de dividendos con excedentes de que gozan los accionistas de la "serie B" del banco, se ha extinguido por haber operado una condición resolutoria, lo cual transforma a dichas acciones en ordinarias. El banco demandado opuso a

\footnotetext{
${ }^{34}$ Sobre el particular, véase: Fernández del Pozo, L. (2001): “¿Cubre la cláusula estatutaria de arbitraje las controversias sobre validez de transmisión de acciones o participaciones? Comentario a la sentencia de la audiencia provincial de Barcelona, 20 de nov. 2000, en: Anuario de Justicia Alternativa ( $\left.\mathrm{N}^{\circ} 2\right)$, pp. 136 y ss.
} 
la demanda, entre otras, la excepción dilatoria del Art. 303 № 1 del Código de Procedimiento Civil, esto es, la incompetencia absoluta del Tribunal, la que funda en que mediante escritura pública otorgada ante notario público, que contiene el estatuto refundido que en el futuro regirá al Banco y que expresamente sustituye el anterior, estipula en una de sus cláusulas que las diferencias que ocurren entre los accionistas en su calidad de tales o entre estos y la sociedad o sus administradores, sea durante la vigencia de la sociedad o durante su liquidación serán sometidos a la resolución de árbitros arbitradores nombrados uno por cada parte".

e. Por otra parte, debemos considerar que el pacto de sociedad se concibe como un contrato de larga duración sometido, por tanto, a las fluctuaciones del mercado y donde es habitual la existencia de lagunas (iniciales y sobrevenidas) en su formulado que requieren de algún mecanismo de integración. En tal sentido, surge la pregunta de si los árbitros podrían, dentro de sus funciones, adaptar los contratos a las nuevas circunstancias. Se trata de una función que emerge como consecuencia del creciente desarrollo industrial y tecnológico, así como por la inversión y contratación por parte de empresas, incluso de organismos públicos de los Estados industrializados con los Estados en vías de desarrollo ${ }^{35}$. Se trata de una materia que perfectamente podría ser encomendada a los árbitros si son nombrados con la calidad de arbitrador, porque su competencia y posibilidades de actuación se amplían en relación al árbitro de derecho.

Otro cuestionamiento relevante es determinar si el árbitro puede dirimir los empates sistemáticos que puedan producirse en los acuerdos sociales y de directorio si se encuentran facultados para ello ${ }^{36}$. Frente a ello, debemos considerar que se trata de materias reservadas normalmente a la resolución de ciertos órganos administrativos por ley o bien, por estatutos (Art. 47 LSA), de manera que, aun cuando se considere que los árbitros no son competentes para dictar un laudo que sustituya la voluntad social, ni administrativa, sí lo serán para declarar, a instancia de socios o administradores, la disolución de la sociedad por paralización de los órganos sociales que hagan imposible su funcionamiento ${ }^{37}$.

f. Cabe precisar que la eventual aplicación de una norma de orden público a la solución de la controversia societaria no excluye necesariamente al arbi-

\footnotetext{
35 Véase: Calvo Caravaca, Alfonso; Fernández de la Gándara, Luis (1989): El arbitraje comercial internacional (Madrid, Ed. Tecnos), p. 26.

${ }^{36}$ Carazo Liébana, María José (2005): El arbitraje societario (Madrid, Ed. Marcial Pons), p. 48, cita a Senén de la Fuente quien se pronuncia afirmativamente sobre esta materia; en contra se pronuncia MuÑOz Planas, José María (1978): "Algunos problemas del arbitraje en materia de sociedades mercantiles", en: Estudios de Derecho Mercantil en homenaje a Rodrigo Uria (Madrid, Editorial Civitas), pp. 48-49.

${ }^{37}$ Carazo Liébana, María José (2005): El arbitraje societario (Madrid, Ed. Marcial Pons), p. 49.
} 
traje estipulado, pero condiciona al árbitro a su correcta aplicación. Para ello se debe considerar que el argumento del "interés social" -algún día pregonado como límite del arbitraje- se encuentra en completo abandono (frente a una tesis institucional aquél sería una síntesis de diversos intereses: el de los socios, trabajadores, consumidores, economía nacional, etc.), hoy en día, a fuerza del cambio de este paradigma hacia el meramente contractual, el único interés a considerar es el común de los socios o de valor para el accionista, esto es, la maximización del valor de la empresa entendida como incremento del valor de la participación del socio.

g. Finalmente, en relación a la arbitrabilidad subjetiva, esto es, las partes que resultan obligadas, el problema que se presenta liga con la vinculación de los nuevos socios a la cláusula arbitral. Frente a ello, hemos de recordar que sobre esta materia, a diferencia de lo que acontece en Derecho comparado, no existen diferencias entre el socio fundador y los socios no fundadores ya que de conformidad al Art. 22 de la LSA "La adquisición de acciones de una sociedad implica la aceptación de los estatutos sociales", de manera que la cláusula arbitral será obligatoria para el socio adquirente por disposición de la ley, sin necesidad de probar que éste tenía conocimiento respecto de aquella al momento de efectuar la compra de acciones. El convenio arbitral extraestatutario, en cambio, implica que el pacto arbitral no ha sido incluido en los estatutos sociales, sino que forma parte de un pacto independiente. Una diferencia relevante entre ambos se percibe en cuanto al alcance de sus efectos, toda vez que el arbitraje estatutario, al formar parte del contrato social, desplegará su eficacia frente a terceros vinculando a los socios presentes y futuros, además de terceras personas como a la sociedad a través de sus órganos sociales, mientras que el arbitraje contenido en un pacto independiente sólo presenta una eficacia inter partes, es decir, sus efectos se extienden sólo entre quienes participaron del mismo. En tal sentido, el acuerdo arbitral inserto en un pacto parasocial o extraestatutario se vinculará con los conflictos sociales a los que se refiere expresamente y, por regla general, sólo vinculará a los adquirentes de las acciones si puede demostrarse que expresa o implícitamente prestaron su consentimiento, lo que incluye la posibilidad que el convenio se entienda incorporado por referencia al acuerdo entre las partes. Una excepción a esta regla la constituyen los acuerdos de la junta de accionistas que contienen una cláusula arbitral, toda vez que de conformidad al Art. 22 de la LSA, tales acuerdos también son vinculantes a los futuros socios por la sola adquisición de acciones de la sociedad

\section{Algunas reflexiones para finalizar}

El Derecho societario y el Derecho arbitral están viviendo un especial proceso de modernización, tanto desde una perspectiva internacional como doméstica. 
En este escenario, resulta relevante tener presente que ambos se encuentran especialmente conectados, fundamentalmente porque el primero requiere de una justicia especializada y eficaz, rasgos que se atribuyen normalmente al arbitraje.

Como ha quedado de manifiesto, la arquitectura normativa dispuesta en el Derecho societario chileno relativo al arbitraje es confusa, contradictoria e inadecuada, de manera que se precisan cambios modificatorios importantes, comenzando por la derogación del arbitraje obligatorio y una articulación normativa acorde a estos tiempos, que resuelva las materias más importantes que han de considerarse a estos efectos, como acontece con la arbitrabilidad. Solo así podremos llegar a sostener que el Derecho societario se ha modernizado en este campo de acuerdo a la realidad y necesidades de estos tiempos. 